\title{
Guerrilha digital e produção de contranarrativas: resistindo aos impactos dos mecanismos de dominação de memória na internet
}

\author{
RENATO DE LYRA LEMOS \\ Universidade Federal de Pernambuco, Recife, Pernambuco, Brasil \\ renatoll@gmail.com
}

DOI 10.11606/issn.2316-9133.v29i2pe175020

\begin{abstract}
resumo Este texto tem como premissa compreender o papel que as Tecnologias de Informação e Comunicação (TIC's) exercem em nossa sociedade a partir das perspectivas dos conflitos existentes entre a construção de memórias e a produção de conhecimento e os impactos provenientes das experiências da falha, do colapso tecnológico, do reparo e da exclusão digital, aliados aos mecanismos de controle do capitalismo de dados, como a regulação algorítmica, no processo de marginalização de diversos grupos sociais. Serão apresentadas também as táticas de guerrilha digital empreendidas por esses grupos e indivíduos com o intuito de promoverem as suas contronarrativas.
\end{abstract}

palavras-chave Tecnologias de Informação e Comunicação. Colapso tecnológico. Regulação algorítmica. Exclusão digital.

Digital guerrilla and counter-narrative production: resisting to the impacts of memory domination mechanisms on the internet

abstract The article's purpose is to understand the role that Information and Communication Technologies (ICT's) play in our society. Its start point is the perspectives of conflicts between the construction of memories and the production of knowledge and the impacts resulting from the experiences of failure, technological breakdown, repair and digital exclusion, combined with mechanisms of control of data capitalism, such as algorithmic regulation, in the process of marginalization of different social groups. It also presents the digital guerrilla tactics undertaken by these groups and individuals in order to promote their counter-narratives.

keywords Information and Communication Technologies. Technological collapse. Algorithmic regulation. Digital exclusion. 
La guerrilla digital y la producción antinarrativa: resistir los impactos de los mecanismos de dominación de la memoria en Internet

resumen Este texto busca comprender el papel de las Tecnologías de la Información y la Comunicación (TIC) en nuestra sociedad. La perspectiva es la de los conflictos que existen entre la construcción de memorias y la producción de conocimiento y los impactos derivados de las experiencias de fracaso, colapso tecnológico, reparación y exclusión digital, aliado a los mecanismos de control del capitalismo de datos, como la regulación algorítmica, en el proceso de marginación de diferentes grupos sociales. También se presentarán las tácticas de guerrilla digital emprendidas por estos grupos e individuos con el fin de promover sus contranarrativas.

palabras clave Tecnologías de la información y la comunicación. Colapso tecnológico. Regulación algorítmica. Exclusión digital.

\section{Introdução - "A tecnologia é sempre eficaz, se ao menos seus usuários não fossem tão falíveis..."}

Enquanto escrevo esse texto o mundo está passando por uma pandemia em escala global causada pela disseminação da doença respiratória COVID-19. Uma parcela significativa da população mundial se encontra nesse momento em isolamento social, reclusa em suas residências. Escolas, empresas, comércios e locais públicos estão fechados ou com acesso restrito. Isoladas em seus lares, as pessoas tentam manter uma parte de seus cotidianos, e muitas de suas atividades rotineiras têm sido possibilitadas através do uso das Tecnologias de Informação e Comunicação. Por meio destas, as pessoas conseguem trabalhar, fazer compras, conversar com seus parentes e amigos, entreterem-se, estudar. Ou seja, teoricamente, mesmo com as pessoas dentro de casa, o mundo continua em plena atividade. Mas, e todas aquelas pessoas que não têm acesso à internet ou que mesmo quando possuem, este ocorre de modo ineficiente e falho?

Até o final de 2019, a International Telecommunications Union estimava que 53,6\% ${ }^{1}$ (ITU 2020) da população mundial dispunha de acesso à internet. Isso quer dizer que quase metade das pessoas no globo não dispunham de nenhum tipo de acesso a essas ferramentas, sendo isoladas digitalmente. Quando vemos notícias sobre os impactos que as Tecnologias de Informação e Comunicação (TIC’s) vêm exercendo na contemporaneidade sobre a construção do conhecimento, geralmente estas apresentam um caráter favorável sobre como essas novas tecnologias podem suprir lacunas e otimizar o tempo e as formas de se adquirir e construir conhecimentos. Esse tipo de visão leva em conta ideias como a comodidade do

\footnotetext{
${ }^{1}$ Informação disponível em: https://www.itu.int/en/ITU-D/Statistics/Pages/facts/default.aspx.
} 
uso de aparelhos tecnológicos, a velocidade do tráfego de informações através da internet, a possibilidade de acessar informações em lugares distantes e a abundância de conteúdos os quais podem ser acessados através da internet.

Assim, as TIC's e especialmente a internet são vistas como solução para diversos problemas que têm em suas bases questões sociais e infraestruturais muito mais amplas, como se essas questões pudessem ser solucionadas apenas através de um levantamento maior de dados, os quais retroalimentariam o sistema e através da análise realizada pelos algoritmos possibilitaria uma aplicação "adequada" das tecnologias. Essa perspectiva, denominada de "messianismo digital" (ALZOUMA 2011) solucionismo (MOROZOV 2018) ou ainda “pensamento computacional” (BRIDLE 2019), é responsável por erigir uma visão da internet como uma ferramenta de transformações sociais (LOVELUCK 2018), que poderia proporcionar a partir de sua arquitetura e infraestruturas a solução para diversos problemas sociais que afligem a humanidade contemporaneamente, os quais tem sua origem anterior à criação e difusão da internet, como se fosse necessário apenas a "simples aplicação de princípios de engenharia” (VAIDHYANATHAN 201: p.13). Essa perspectiva acaba gerando uma fé cega nas inovações tecnológicas e consequentemente a culpabilização do usuário por qualquer tipo de "falha", visto que ao caracterizar as tecnologias como sempre eficazes, qualquer erro ocorrido no processo seria culpa do usuário, ao não conseguir utilizar essas ferramentas apropriadamente, atribuindo a sua experiência como um "fracasso" (APPADURAI; ALEXANDER 2020: p.2).

Outra problemática associada a essa construção é a visão de que através da internet as informações estariam acessíveis a apenas alguns cliques de distância. Esse é um tipo de ideal que não é necessariamente incorreto, porém bastante impreciso. Realmente existe hoje a possibilidade de que as informações possam ser acessadas a apenas alguns cliques. Mas a questão é: por quem? Esse tipo de ponto de vista não costuma levar em conta que uma parcela significativa da população ao redor do globo não possui acesso à internet e às suas tecnologias, ou quando possui, esse se dá de forma limitada, debilitada, ineficiente e insatisfatória. Uma série de fatores sócio-históricos, que estão dentro do panorama de exclusão social do qual temos amplo conhecimento, que impossibilita e isola indivíduos e comunidades de terem acesso mais amplo ao tecnoutopismo do mundo globalizado ou aldeia global eletrônica (Y’AU 2004), também se mostram presentes quando falamos sobre as Tecnologias de Informação e Comunicação.

Dentro do conjunto desses fatores históricos de exclusão, temos a influência de uma série de elementos infraestruturais como a dificuldade no acesso a dispositivos tecnológicos, a falta de habilidades requeridas para um uso apropriado destes, ausência de tempo disponível para sua utilização, o alto custo de acesso à internet e a instabilidade na rede elétrica das localidades e mesmo a carência de uma formação social e escolar que possibilite um uso profícuo dessas tecnologias. Ou seja, é uma junção de aspectos infraestruturais

\footnotetext{
${ }^{2}$ Do original "failure" em inglês, que dependendo do contexto em que está sendo utilizado poderá ser traduzido como "falha" ou como "fracasso".
} 
técnicos e também sociais que causam essas adversidades (SRINUAN; BOHLIN 2011). Todos esses fatores devem ser considerados quando estamos falando sobre o acesso às tecnologias e a construção do conhecimento, e afinal, quando levamos isso em conta, a característica democrática da internet não se demonstra assim tão mais evidente. Como então essas tecnologias conseguiriam resolver os problemas sociais desses grupos se eles nem ao menos têm acesso a elas?

\section{Experiências digitais mediadas pela exclusão e pelos regimes de falha}

Alguns autores e autoras partem da perspectiva da existência de uma lacuna entre os indivíduos que possuem amplo acesso às TIC's e os que não o possuem, o que denominam como "Divisão digital" ou "Exclusão digital" (CASTELLS 2003; FUCHS; HORAK 2008; BAGULA et al 2011; PICK; SARKAR 2015; DESTA 2018). Essa impossibilidade ou disparidade no acesso às TIC's, delimitada pelas barreiras infraestruturais, gera o que outros e outras conceituam ainda como "fosso digital" (MOLINARI 2011). Essas premissas partem da perspectiva de que a diferença existente entre esses grupos é tão grande que ela se torna praticamente intransponível.

Esses processos de exclusão, em uma época substancialmente digitalizada, em que o acesso a alguns bens e serviços só é possível através de/ou são facilitados pelo uso da internet e suas tecnologias, faz com que os indivíduos que não possuam amplo acesso a estas ferramentas acabem sendo excluídos/marginalizados. Assim, estes sujeitos tendem a serem menos informados/as, terem menos possibilidades de se inserirem no mercado de trabalho e menos chances de terem suas produções, ideias e visões de mundo transmitidas em larga escala (MOLINARI 2011). Assim como no mundo analógico, do qual o universo digital faz parte, a internet ao invés de ajudar a diminuir as barreiras sociais acaba muitas vezes reforçando-as. O projeto de exclusão social implementado pelas elites é reforçado, deste modo, através dos meios digitais, os quais são amplamente controlados por estas.

Sob essa perspectiva, que tipos de conhecimentos são esses que são produzidos, que tipos de memória são essas que são arquivadas? A desconstrução da internet enquanto espaço democrático de disputas pelas memórias contribui para reforçar que a luta pelas narrativas ainda se mantém em jogo. Mas afinal, será que o status das relações de poder tem conseguido se modificar significativamente através do uso dessas novas tecnologias por grupos socialmente excluídos?

Os arquivos, enquanto locais físicos onde são guardados os documentos que registram a história da humanidade, são formados por documentos e objetos os quais antes de serem depositados ali são cuidadosamente selecionados, passando por uma triagem a qual, em seu desfecho, o que o processo de curadoria dos(as) pesquisadores(as) e arquivistas decidem em manter como digno de ser conservado, e que, desse modo, irá compor o arquivo, acaba se apresentando infimamente reduzido em comparação com o que é descartado. $\mathrm{O}$ arquivo assim passa a ser mais um status do que um dado (MBEMBE 2002). 
O processo de curadoria, que envolve o julgamento do que merece ou não ser preservado, passa por escolhas as quais são determinadas através das relações de poder (BEARMAN 2002; HAMILTON 2002; HARRIS 2002; SCHWARTZ; COOK 2002). São essas relações de poder, mediadas pelos processos pessoais contidos na subjetividade dos e das arquivistas, que vão determinar o que vai ser preservado e, portanto, delimitam os conteúdos que irão formar os acervos dos arquivos, e junto a isso, os modos como poderão ser contadas as histórias no futuro.

As Tecnologias de Informação e Comunicação, por mais que não sejam amplamente acessíveis, ainda sim, demonstram-se como ferramentas através das quais torna-se possível que outras histórias sejam lidas, vistas, ouvidas e contadas. Por mais que o crivo do poder sempre esteja presente ali em algum momento, ainda assim, abrem-se a oportunidades que em outros períodos históricos não seriam possíveis, devido ao amplo e quase irrestrito controle desse tipo de ferramenta nas mãos dos Estados e das elites. Ainda mais nos últimos anos, com um amplo acesso da população mundial a aparelhos celulares, as ferramentas tecnológicas, mesmo evidentemente não democratizadas, já se mostram mais acessíveis.

Ao mesmo tempo, que o acesso se torna mais amplo, os mecanismos de controle também se ampliam, como o "capitalismo de vigilância" e a "opressão algorítmica" dos quais falarei mais à frente. Além disso, é evidente que essa "acessibilidade" tecnológica se dá dentro do panorama infraestrutural precário que já mencionei, gerando uma dialética do colapso tecnológico e do reparo (LARKIN 2005) e um regime de falha/fracasso (APPADURAI; ALEXANDER 2020), isto é, um sistema em que a infraestrutura instável e ineficiente de acesso à internet e de suas tecnologias e a suas constantes falhas e necessidades de reparo se demonstram como um padrão regular e repetitivo de experiência para diversas comunidades e grupos sociais, e mesmo algo almejado pela indústria através de uma obsolescência planejada dos equipamentos a qual visa uma maior rotatividade na aquisição de modelos atualizados (APPADURAI; ALEXANDER 2020). Ou seja, mesmo que as tecnologias de uso da internet estejam significativamente desenvolvidas, elas não têm como serem devidamente acessadas por boa parcela da população devido à estruturação do sistema através dos regimes de falha.

Esse tipo de experiência, evidentemente, contribui para delimitar as formas de uso da internet por boa parte da população global. Afinal, de que adianta uma informação estar a "apenas alguns cliques de distância" como afirmei no início do texto, se o acesso à internet é lento, o sistema não consegue carregar o site onde está hospedada aquela informação, o computador trava ou mesmo a energia cai e o equipamento queima? Essa experiência do colapso tecnológico é mais comum do que pensamos, e ainda mais comum para uns e umas do que para outros/as. Desse modo, como poderíamos afirmar uma suposta democracia da internet?

\section{Compreendendo as infraestruturas e as lógicas de formação de arquivos digitais}


Determinados pesquisadores e pesquisadoras veem a digitalização dos patrimônios culturais como uma possível solução para sua democratização e acessibilidade (THRAM 2002; NANNYONGA-TAMUSUZA; WEINTRAUB 2012). Mas será que apenas isso basta? Afinal, como já assinalei, de que adianta uma informação estar "acessível" se as pessoas não dispõem de meios e recursos para acessá-la? Porém, ainda assim, acredito que a digitalização de determinados conteúdos seja uma etapa importante nesse processo, por mais que não seja a mais significativa. Afinal, se mesmo estando acessíveis em bancos de dados digitalizados e disponibilizados na internet esses bem culturais não têm sido acessados por determinados grupos, imagine se elas fossem disponibilizadas apenas fisicamente nos cofres de arquivos em instituições espalhadas pelo mundo? Quem teria disponibilidade para acessá-las? A digitalização desses arquivos, então, viabiliza uma série de possibilidades que devem ser maximizadas através de uma real democratização das tecnologias de informação e comunicação.

Mas, afinal, quando acervos de coleções e arquivos são digitalizados e o seu acesso torna-se possibilitado através da internet, quem se beneficia com isso? (THRAM 2002). Em geral são os mesmos grupos dos quais as histórias sempre foram contadas, ou que foram responsáveis por contar as histórias dos "outros". Se apenas os mesmos grupos continuam acessando e produzindo conteúdo, acabamos, assim, perpetuando um mesmo modelo em que o acesso ao conhecimento só é possibilitado através do poder e onde a visão de mundo dos poderosos torna-se a única forma de conhecimento possível e acessível. Existiriam assim outros meios de produzir e acessar conhecimento fora desse padrão de repetição vicioso?

Como a questão do acesso às tecnologias de informação e comunicação se tornou uma preocupação mundial, fazendo com que a exclusão digital seja considerada uma nova forma de analfabetismo (MOLINARI 2011), junto aos desenvolvimentos das tecnologias foram surgindo projetos que visavam dar conta de uma democratização do acesso a essas tecnologias. Nessa perspectiva surgiram programas como o One Laptop Per Child (KRAEMER; DEDRICK; SHARMA 2009), proposto por duas organizações sem fins lucrativos que tinham como objetivo construir um computador portátil, durável, de baixo custo e acessível, que facilitasse o processo de aprendizado das crianças; e os centros da Red de Innovación y Aprendizaje (MOLINARI 2011), que tem por proposta a construção de centros comunitários onde são ofertados cursos de formação e disponibilizados computadores para serem utilizados comunitariamente, visando diminuir os índices de exclusão digital.

Essas iniciativas, mesmo somadas a diversas outras, ainda assim não tem conseguido suprir a alta demanda de acesso à internet pela população global, por mais que os modelos voltados ao uso comunal tenham obtido certo êxito em suas empreitadas. Porém, mais do que apenas o acesso a essas ferramentas, são necessários outros tipos de intervenção mais significativas em suas possibilidades de uso, como veremos mais à frente. Porém, além da acessibilidade, há outros grandes problemas que também evolvem a questão digital, como o 
processo de informacionalização da nossa sociedade e da ascensão do "capitalismo de dados" (MOROZOV 2018) ou "capitalismo de vigilância" (ZUBOFF 2018; 2019).

$\mathrm{Na}$ contemporaneidade, os dados são um importante instrumento de dominação. Estes dados são adquiridos pelas chamadas empresas Big Tech, que controlam as plataformas digitais, seja fornecidos por nós carrengando-os nessass plataformas ou minerados pelas empresas através dos resíduos deixados por nós na utilização dessas mesmas plataformas. São dados relativos à nossa utilização das ferramentas digitais conectadas à internet e que permitem que essas empresas acompanhem nossos perfis de consumo, lazer, gostos pessoais, relações sociais, etc. Esses dados então são processados através de algoritmos, agregados e correlacionados para criar padrões de compreensão das nossas atividades digitais, numa tentativa de prever nossos comportamentos e mesmo moldá-los.

A lógica de estruturação dos usos da internet é moldada pelos algoritmos dos aplicativos, para estabelecer um referencial de uso que vai guiando o(a) usuário(a) a acessar mais daquele tipo de conteúdo que ele(a) costumeiramente acessa, impulsionando para que permaneça mais tempo conectado(a) acessando as informações de seu gosto pessoal ou de interesse do mercado, e de certa forma inibindo-o(a) de acessar outros tipos de conteúdo. Esse direcionamento nos tipos de conteúdos acessados são estratégias de controle utilizadas pelo capitalismo de vigilância como forma de conhecer e posteriormente moldar os nossos comportamentos na rede de forma que estes se tornem mais lucrativos para as empresas que os utilizam (ZUBOFF 2019).

A mediação de conteúdos que inicialmente era realizada pelos próprios usuários e usuárias passou a ser mediada pelos algoritmos e até mesmo amplamente delimitada por eles. E aí reside também outra estratégia de controle que é a "regulação algorítmica" (CHENEYLIPPOLD 2017; MOROZOV 2018). A regulação algorítmica é essa tentativa de dar sentido aos dados obtidos de nós através dos algoritmos e estabelecer através destes um sistema de resolução de questões mercadológicas e sociais que retire a decisão humana da equação, visto que esta seria considerada como não objetiva, gerando formas de vigilância e controle que seriam consideradas assim mais eficazes.

Porém, aí reside um problema muito grande pois esses mecanismos não conseguem dar conta da subjetividade e complexidade humanas, tentando apenas solucionar os problemas sem entender suas causas, o que causaria uma "opressão algorítmica" (NOBLE 2018). A opressão algorítmica parte da perspectiva que as plataformas digitais não são neutras, pois elas são desenvolvidas por pessoas, as quais incluem em sua constituição dos algoritmos as suas visões de mundo. Essas formas de perceber o mundo muitas vezes acabam reproduzindo práticas sociais opressoras que possibilitam uma maior opressão a grupos historicamente marginalizados, visto que em geral estes grupos e suas visões de mundo não costumam estarem presentes na constituição desses algoritmos, inclusive por não serem de interesse não só dos indivíduos que constroem os códigos, como das empresas que os utilizam (NOBLE 2018). 
Além disso, os algoritmos para dar conta dessas questões, necessitariam de intervenção humana constante para alcançar um status de equidade através de sua calibração. A calibragem permitiria introduzir nos algoritmos elementos relacionados às causas daquelas questões que eles estão tentando solucionar, o que possibilitaria implementar uma referência de equidade nesses processos. Porém, a arquitetura dos algoritmos é estruturada para atuar através da retroalimentação, onde à medida que cada vez mais dados seriam obtidos pelo sistema ele conseguiria gerar uma auto-calibragem. Quando um sistema apenas se auto-calibra para estabelecer as suas próprias soluções sem levar em conta as causas, ele pode acabar resolvendo questões sociais apenas através da punição, sem resolver as causas que levam a que estas ocorram. Isso nos traz a questão de que ao lidarem com estatística matemática, ao invés de pensarmos que esses mecanismos estão sendo objetivos, temos de levar em conta que os resultados são tendenciosos (SUMPTER 2019).

Essa estrutura faz parte também dos paradigmas de navegação estabelecidos pelos primeiros usuários e usuárias da internet, pessoas favorecidas no acesso e em geral pertencentes a grupos socialmente privilegiados, que foram responsáveis por formatarem os padrões de utilização da internet. Assim, esses padrões tiveram de ser obedecidos pelos utilizadores que vieram em seguida e, não sendo devidamente adequados à diversidade destes e destas, permitiram a manutenção de um sistema de exclusão (CASTELLS 2003). Porém, outros modelos de utilização têm sido elaborados, os quais visam suplantar esse padrão vigente.

Muitas pessoas que fazem uso da internet não têm conhecimento das possibilidades das ferramentas existentes e da amplitude de informações e serviços os quais podem ser acessados através do uso de um computador ou celular. Algumas pesquisas realizadas nos últimos anos (DESTA 2018; MOLINARI 2011; SPYER 2017) apontam que o uso mais expressivo que as pessoas vêm realizando da internet é de redes sociais e de plataformas de entretenimento de jogos, músicas e vídeos. Por mais que a utilização dessas plataformas seja muito necessária, é importante que, devido ao tempo que muitas pessoas empregam em sua utilização, haja uma maior conscientização sobre o poder do alcance que o uso de outras ferramentas podem abranger.

Uma coisa é saber que essas ferramentas podem existir e estar disponíveis, a outra é ser orientado para saber acessá-las e utilizá-las, adaptando-as às suas realidades. E aí é onde reside o perigo potencial da internet, pela sua possibilidade de ser utilizada como ferramenta de mudança. Nos últimos anos temos visto os usos das ferramentas tecnológicas como aparatos que possibilitem uma maior representatividade, através de uma sucessão de indivíduos e grupos considerados sub-representados nas mídias tradicionais e que têm conseguido ter voz e visibilidade através das redes sociais e outras novas mídias; como ferramentas de denúncia social, como nos casos de práticas de violência policial e abuso de poder; e de mobilização comunitária, como nos levantes políticos ocorridos ao redor do mundo nos últimos anos como o Occupy Wall Street e a Primavera Árabe (CASTELLS 2003). 
Plataformas como o Youtube, Facebook, Instagram, entre outras, mesmo com todo o aparato da regulação algorítmica têm possibilitado que sujeitos e sujeitas que estão fora das grandes mídias sejam vistos/as e ouvidos/as, que contem as suas histórias e das suas comunidades, possibilitando assim a disseminação de outros olhares sobre o mundo, de saberes que fogem ao que nos foi convencionado como "padrão". Mesmo com todo o controle dos aparatos industriais e governamentais, versões alternativas dos acontecimentos têm sido a certa medida contadas nos últimos anos, e mesmo não tendo o apelo massivo dos meios tradicionais, tornam-se também fontes de informação, se manifestando como outras versões possíveis. A própria Wikipedia, enciclopédia colaborativa virtual, mesmo com toda a desconfiança que costumam atribuí-la enquanto uma possível fonte segura de informação, possibilita que conteúdos os quais sempre foram sistematicamente excluídos das enciclopédias físicas estejam agora acessíveis e possam ser produzidos colaborativamente, com a participação inclusive das próprias pessoas as quais estes assuntos dizem respeito.

Assim, mesmo não se tornando uma ferramenta democrática, a partir dessas experiências e táticas de uso, a internet passa a se tornar então um instrumento de possibilidades. E são essas possibilidades que podem favorecer impactos significativos na produção do conhecimento. A partir disso, considero ser muito importante aproveitar o caráter coletivo da internet, através de sua própria estruturação em redes, buscando colaborativamente soluções para questões sociais que atingem diversas comunidades ao redor do globo, beneficiando-se através do compartilhamento de experiências. Por mais utópico que isso possa parecer, essa é uma realidade que vem sendo, dentro das possibilidades, posta em prática nos últimos anos.

\section{Táticas de resistência na internet}

Mesmo quando o acesso à internet tem sido escasso, diversas comunidades ao redor do mundo estabeleceram táticas para reagirem ao sistema. As práticas de pirataria digital são um exemplo disso. Bens culturais que antes eram acessíveis a poucas pessoas passaram a ser acessíveis em larga escala ao redor do globo, seja a baixos custos ou até mesmo gratuitamente. Discos e filmes que eram considerados itens supérfluos na vida de muitos jovens que não tinham como comprá-los passaram a ser baixados gratuitamente na internet e também comercializados em versões piratas de baixo custo no mercado informal. Inclusive alguns antes mesmo de serem lançados oficialmente no mercado (WITT 2015).

Em locais como Bamako, capital do Mali, onde muitos/as jovens não têm condições de adquirir discos e não têm acesso fácil a computadores e internet, as músicas podem ser obtidas através do mercado informal. Comerciantes que fazem reparos em celulares aproveitam os conteúdos dos cartões de memória para formar coleções de músicas, as quais são ampliadas através de conteúdos baixados na internet e posteriormente vendidas em grande quantidade por um custo acessível; são os chamados telechargeurs. Estes indivíduos ficam localizados em pontos de comércio na rua com seus computadores e carregam as 
músicas diretamente nos pendrives ou cartões de memória dos celulares dos e das clientes (KIRKLEY 2015).

Os acervos que compõem essas coleções ou arquivos de música também são abastecidos por gravações de artistas locais registradas de modo informal. Durante as apresentações públicas de músicos e bandas locais, muitos/as jovens utilizam os seus celulares para fazerem áudios e vídeos das performances, posicionando seus aparelhos próximos aos músicos e aos amplificadores e efetuando o registro de algumas canções ou da apresentação na íntegra. Essas gravações são posteriormente trocadas com colegas através do bluetooth (KIRKLEY 2015), postadas em redes sociais ou mesmo socializadas em grupos de Whatsapp (SCHMIDT 2018), promovendo assim redes alternativas de circulação que não dependem das grandes mídias e que podem proporcionar visibilidade a outras formas de produzir e consumir música.

Em outros grandes centros como Lagos, capital da Nigéria, o mercado informal de vendas de filmes piratas cresceu tanto que desenvolveu sua própria indústria de produção e distribuição de filmes, criando um mercado e rede de consumo internos, com filmes contando narrativas locais e tratando sobre questões que fazem parte do cotidiano do público consumidor (LARKIN 2005). A indústria da pirataria nessas localidades e o estabelecimento de padrões alternativos de consumo acabou estabelecendo estéticas próprias em suas produções, como nesse caso da indústria de Nollywood em Lagos, ou mesmo da música tecnobrega no Norte do Brasil, composta muitas vezes de pequenos estúdios de gravação caseiros, equipamentos precários e um sistema de divulgação baseado no boca-a-boca, nas festas, nos(as) vendedores(as) de música que utilizam pequenos carros de som tocando as gravações, nas rádios comunitárias e através da internet.

Essas estratégias que apresentei fazem parte de um panorama em escala global de mecanismos utilizados por cidadãos e cidadãs, aos/às quais é apresentado um modelo de participação social e consumo do qual estes(as) são sistematicamente excluídos e excluídas e, como forma de tentarem se inserir na "aldeia digital global" (que para se ingressar é necessário passaporte, visto e rendimento bancário elevado), integrando-se ou propondo sistemas alternativos, estabelecem suas próprias formas de inserção, estratégias que categorizo como guerrilha digital e as quais refletirei mais à frente. Ao proporem essas táticas, esses indivíduos se mostram cientes de que ou eles constroem coletivamente (e mesmo individualmente) essas demandas e empreendem eles próprios os dispositivos de participação social digital ou continuarão a serem excluídos por um sistema que é evidentemente opressor. Além disso, o processo de digitalização do mundo vem se estendendo e impactando diversas áreas da sociedade e atividades cotidianas, fazendo com que os diversos grupos mesmo não sendo inseridos nessas esferas, estejam sujeitos aos seus efeitos negativos.

As TIC’s foram responsáveis por causar uma verdadeira revolução no modo como os arquivos lidam com os registros contemporaneamente (MNJAMA 2014), devido às facilidades que foram proporcionadas por estas para a criação e manutenção de seus acervos. 
Porém, ao mesmo tempo, foram responsáveis por causarem mudanças drásticas. Existem hoje diversos bens culturais que vêm sendo produzidos e distribuídos unicamente em versões virtuais. Questões como o custo mais baixo de produção, maior facilidade de distribuição e comodidade no acesso e na utilização pelo público consumidor, têm feito com que as versões físicas desses bens muitas vezes acabem caindo em subutilização ou mesmo desuso. Além disso, a digitalização de documentos e mídias visando a sua acessibilidade e durabilidade tem tornado as plataformas digitais os meios preferenciais para se realizar uma pesquisa e acessar itens. $\mathrm{O}$ acesso de bens culturais através de plataformas de streaming, por exemplo, chegou a tal ponto que hoje muitas bibliotecas, fonotecas, videotecas e arquivos não têm conseguido mais adicionar uma infinidade de itens a seus acervos sem com isso infringirem leis de direitos autorais (TSOU; VALLIER 2016). Assim, vários especialistas no assunto têm se reunido constantemente procurando meios de como adequar as bibliotecas e arquivos a essas novas realidades, nas quais os itens que iriam renovar e compor os seus acervos a serem consultados, motivos pelos quais essas instituições existem, não podem mais ser adquiridos e mantidos por estas.

Ao mesmo tempo em que recursos culturais vão também ficando mais concentrados em outros espaços, que a princípio seriam de maior acessibilidade, como as plataformas de streaming de músicas e vídeos, as livrarias digitais com livros e artigos acadêmicos e ainda outros, as pessoas também têm de lidar com questões outras como: ter condições financeiras para acessar esses recursos, vários dos quais são pagos; ou se contentar em acessar apenas os serviços que são gratuitos, e que, portanto, têm acervos bastante reduzidos; ou ainda por último, acabar tendo de optar pela ilegalidade para poder acessar os conteúdos que só são disponíveis de forma paga. Assim, se um indivíduo que já seja beneficiado por ter algum tipo de acesso à internet, mesmo que dentro das perspectivas da falha, do colapso tecnológico e do reparo, não tenha condições financeiras para acessar estes bens culturais pagos, vai continuar a sair em desvantagem em relação às formas de acessar conhecimento em comparação aos grupos privilegiados que sempre tiveram possibilidade de acesso amplo a esses bens.

Como podemos perceber, os mesmos hábitos de exclusão que sempre se repetiram na ciência têm, até certas medidas, sido mantidos nesse panorama de "oportunização" do acesso gerada pelas tecnologias. Porém, esses modelos têm sido danificados gradativamente ou ao menos parcialmente rompidos, pois a mesma "arquitetura organizacional da globalização, que promove a infraestrutura que possibilita que os bens midiáticos circulem [...] gera possibilidades para a sua própria corrupção e parasitismo” (LARKIN 2005: p.46). Ou seja, o sistema que cria uma infraestrutura oficial acaba possibilitando que seja criada também uma outra, extralegal. Infelizmente, só através da transgressão desse sistema e do desenvolvimento dessas novas estruturas é que tem sido possível para muitos grupos acessarem determinados bens culturais e lugares de visibilidade.

Nas Universidades públicas brasileiras é costumeiro que alunos e alunas, não tendo condições de adquirir os livros que serão estudados nas matérias, e não tendo as próprias 
Universidades também livros em quantidade suficiente para todos/as em suas bibliotecas, recorram ao sistema de fotocópias, ou hoje mais amplamente, às cópias digitais dos textos, muitas das quais não obedecendo às leis de reprodução e direitos autorais. A ausência de determinadas leituras nas disciplinas e bibliotecas, seja pela incapacidade ou pela falta de interesse de docentes por essas temáticas, também muitas vezes são supridas pelo acesso a cópias digitais. É uma forma de romper o sistema que pode ter como característica uma abrangência muito maior, a qual amplia-se através das redes digitais.

Trazendo exemplos mais particulares, mas não exclusivos, da situação brasileira, se intelectuais negras e negros e indígenas dificilmente acessam ou são acessados em espaços de poder, essas ferramentas têm colaborado para transformar esse panorama. Iniciativas individuais e coletivas têm surgido visando a digitalização de artigos e livros de intelectuais negras e negros e a sua disponibilização em pastas de acesso virtual, as quais rapidamente são disseminadas através de listas de e-mail, grupos de Whatsapp, perfis de redes sociais de grupos de estudos e de coletivos de militantes, etc. Muitos textos têm sido escritos e instantaneamente publicados e disseminados na internet por indivíduos pertencentes a esses grupos, tornando possível que seus questionamentos e conhecimentos possam ser acessados de maneira mais rápida e profícua, devido, muitas vezes, à demora e mesmo à impossibilidade de publicação destes em livros e revistas acadêmicas. Isso possibilita que as referências dos textos acadêmicos não permaneçam mais "em branco"”.

Nesses tipos de ação se situa uma questão muito importante possibilitada através dos usos das ferramentas digitais. Pois, para além do uso "benéfico" da internet (DESTA 2018) e da "instrução tecnológica" (BRIDLE 2019), voltados, por exemplo, para a inserção dos indivíduos no mercado de trabalho, ou seja, através de um senso de uso prático, de adequação e inserção dentro do sistema, e da adequação a determinadas práticas de uso que seriam vistas como mais eficazes, como na perspectiva da "instrução digital" (FUCHS; HORAK 2008), abre-se a possibilidade de utilização da internet não para se adequar às demandas desse sistema, mas para instituir novas demandas, e fazer com que seja a internet, e, portanto, o sistema, a se adaptar às necessidades desses(as) sujeitos(as). É aí onde reside o uso revolucionário das ferramentas digitais.

\section{Guerrilha digital e hackeamento como resistência cultural}

$\mathrm{O}$ processo de tornar digitais e automatizados recursos que eram previamente analógicos é chamado de "revolução digital" (KRZYWDZINSKI; GERBER; EVERS 2018). Todavia, esse seria um tipo de revolução que beneficia mais diretamente apenas um grupo específico, das elites que têm controle sobre essas tecnologias, deixando assim todo o restante do mundo de fora. No entanto, um processo que não traz vantagens para a grande maioria da população não deveria ser chamado de revolução, visto que as mudanças que ele traz

\footnotetext{
${ }^{3} \mathrm{O}$ jogo de palavras que utilizo aqui da expressão "em branco" é no intuito de atingir dois sentidos. O primeiro é através da concepção de uma página vazia, sem informações, pela ausência de textos que abordem aquelas temáticas, e a segunda é a concepção de que as referências dos textos acadêmicos historicamente costumam conter apenas autores brancos.
} 
acarretam formas de exclusão e desigualdade ainda maiores. Assim, a verdadeira revolução residiria na reestruturação e transformação dessas estruturas, como nos exemplos que demonstrei anteriormente. Porém, devido à dificuldade de uma reestruturação em larga escala, pois mesmo a internet tendo um caráter viral também está exposta à interferência algorítimica, essas intervenções acabam adquirindo características de guerrilha, de ações circunstanciais que visam modificar contextos mais restritos, mas que acabam servindo como protótipos para outras intervenções.

Esse tipo de prática de guerrilha digital ${ }^{4}$, mesmo em se tratando de ações pontuais, passa a ter um caráter multiplicador devido à estruturação em rede, uma característica própria da internet e das ferramentas digitais, através das quais esses exemplos acabam encontrando um modo de circular, sobrepondo as bolhas informacionais, e propiciar assim a formação de novas atividades e ações que vão além da rede inicial em que eles se formaram. São realizações, muitas vezes, inclusive, individuais e não conscientes da necessidade de uma mudança mais ampla do sistema, mas que através do êxito de suas próprias atitudes individualistas acabam servindo como referências para outras ações individuais e/ou coletivas. Ou seja, mesmo que estes indivíduos e grupos não estejam interligados, eles acabam conectados através das redes digitais, e suas ações acabam sendo reverberadas para a coletividade.

Não necessariamente essas atividades se encaixam na perspectiva do ciberativismo, pelo motivo que já apontei de que podem ser ações feitas visando ao benefício próprio, sem pensar em uma causa mais ampla ou nos proveitos que isso pode acarretar para a coletividade. Por isso, essa definição de guerrilha, pela atividade de ações descontínuas e não necessariamente interligadas por uma rede, mas que acabam se conectando por seu caráter de experiências análogas e tomando o aspecto de um movimento coletivo e até mesmo global; de guerrilhas digitais.

Obviamente, não é fácil, apenas através das atividades de guerrilha digital, estabelecer uma mudança radical no sistema, pois para isso seriam necessárias ações muito mais amplas, inclusive nos âmbitos empresarial e governamental. As políticas neoliberais também, nem de longe, têm sido parte da solução, pois mesmo gerando um maior mercado e com preços teoricamente mais acessíveis, têm contribuído amplamente para uma manutenção das diferenças sociais, mantendo as classes mais pobres excluídas desse processo ao não possibilitar a redistribuição de renda (FUCHS; HORAK 2008) e pela manutenção do poder nas mãos de pequenas elites tecnológicas. Assim, pela realidade que temos vivenciado, sabendo que é muito difícil que ocorram esses tipos de intervenção, restam então o desenvolvimento e propagação dessas táticas alternativas.

Essas táticas podem ser entendidas também através do conceito de pirataria; a criação de um sistema de cópias não-autorizadas e redes de distribuição alternativas, como uma

\footnotetext{
${ }^{4}$ Emprego a perspectiva de Guerrilha Digital a partir do conceito de Guerrilha Cultural utilizado pelo compositor e artista plástico paraibano Pedro Osmar, de ruptura com o sistema dominante através da transgressão.
} 
lógica de insurgência cultural através da qual os arquivos históricos são hackeados mediante o estabelecimento de novas narrativas que visam desautorizar o que está contido neles (JAJI, 2014). Assim, a circulação dos textos culturais que seriam resultantes dessas práticas possibilitaria uma rede de solidariedade através da qual as experiências podem ser articuladas e conectadas visando consequências significativas para a estruturação de uma resistência ao sistema. Desse modo, o hackeamento afirma-se como uma estratégia possível para "reivindicar nosso direito de agência cultural" (BUSSEY 2017: p.89) através da utilização de ferramentas que possam intervir e reconfigurar os sistemas dominantes.

A utilização da ideia do hackeamento como uma arma a ser utilizada na guerrilha digital visa estabelecer uma nova esfera de insurgência cultural para combater os "conglomerados de tecnologia e finanças" que tentam impedir o nosso acesso ao "tipo de conhecimento compartilhado e educação necessária para a resistência política" (APPADURAI; ALEXANDER 2020: p.29). E é através dessa perspectiva que reside o desafio de criar conteúdos, especificamente, novas formas de conteúdo como propostas intervencionistas a toda a informação e formas de narrativa que foram historicamente impostos a esses grupos, do que apenas acessá-los e consumi-los sem reflexão crítica.

Assim, ao mesmo tempo em que necessitamos de uma maior liberdade para o acesso, a produção e a disseminação de conteúdos na internet (ASSANGE 2013), com o intuito de dar visibilidade às contranarrativas de grupos marginalizados, também precisamos pensar nos modos problemáticos com que estes mesmos grupos continuam sendo continuadamente subrepresentados na internet, de maneira estereotipada e preconceituosa, e nos direitos de controle desses grupos sobre suas memórias como uma questão também de regulamentação da internet e implementação de políticas públicas (NOBLE 2018).

Também é necessário desenvolver o estímulo a uma maior compreensão do funcionamento da internet e de suas infraestruturas, não através da "instrução tecnológica" para saber utilizá-las, mas de um processo de "alfabetização", visando compreendê-las, criticá-las e moldá-las, como forma de se opor ao "pensamento computacional" (BRIDLE 2019), pois se a internet hoje consegue realmente dar conta de resolver algo, é apenas dos problemas do mercado e das elites. Ao invés da ideologia de "emancipação" que é pregada pelas empresas de tecnologia, o que essas ferramentas têm produzido é a nossa dependência em uma escala cada vez maior.

Por isso tudo é necessário que proponhamos a reflexão sobre os efeitos e impactos que essas tecnologias vêm causando em nossa sociedade. Afinal, continuar consumindo e produzindo conhecimento por meio dessas ferramentas sem propor uma mudança significativa ao que vem sendo elaborado, e nos possíveis impactos que isso pode causar na sociedade, acaba apenas contribuindo para a manutenção de uma ordem vigente, e subvertendo o sentido efetivo que deveria estar contido na busca do conhecimento, que é o da emancipação do ser humano, pelo acesso a um grande volume de conhecimento, mediado pelos algoritmos, que não nos leve a refletir e causar efetivo impacto em nossas realidades, diferenciando assim, a informação do saber (HAN, 2018). 


\section{Referências Bibliográficas}

ALZOUMA, Gado. (2011). Young People, Computers and the Internet in Niger. Journal of African Media Studies. Vol 3, Issue 2.

APPADURAI, Arjun; ALEXANDER, Neta. (2020). Failure. Cambridge: Polity Press.

ASSANGE, Julian; APPELBAUM, Jacob; MULLER-MAGUHN, Andy; ZUMMERMAN, Jérémie. Cypherpunks: liberdade e o futuro da internet. São Paulo: Boitempo.

BAGULA, Antoine; ZENNARO, Marco; NUNGU, Amos; NKOLOMA, Mayamiko. (2013). Bridging the Digital Divide in Africa: A Technology Perspective. Wireless Communication and Information Conference, 2011.

BEARMAN, David. (2002). Electronic Record-keeping, Social Memory and Democracy. In: HAMILTON, Carolyn et al. Refiguring the Archive. London: Kluwer Academic Publishers.

BRIDLE, James. (2019). A nova idade das trevas: a tecnologia e o fim do futuro. São Paulo: Todavia.

BUSSEY, Marcus. (2017). \#HackFutures: Futurist As Hacker. Journal of Futures Studies, Vol.22, $\mathrm{n}^{\circ} 1$.

CASTELLS, Manuel. (2003). A galáxia da internet: reflexões sobre a internet, os negócios e a sociedade. Rio de Janeiro: Zahar.

CHENEY-LIPPOLD, John. (2017). We Are Data - Algorithms And The Making Of Our Digital Selves. New York: New York University Press.

DESTA, Tedla. (2018). Comments on the Digitalization and Digital Divide in the Horn of Africa (HoA), Kenya and Ethiopia: The Media Perspective. Global Media Journal, v.16, n.30, ed. 92.

FUCHS, Christian; HORAK, Eva. (2008). Africa and the digital divide. Telematics and Informatics, v. 25, n.2.

HAMILTON, Carolyn. (2002). 'Living by Fluidity': Oral Histories, Material Custodies and the Politics of Archiving. In: HAMILTON, Carolyn et al. Refiguring the Archive. London: Kluwer Academic Publishers.

HAN, Byung-Chul. (2018). No enxame: perspectivas do digital. Petrópolis: Vozes.

HARRIS, Verne. (2002). The archival sliver: Power, memory, and archives in South Africa. Archival Science, v.2, n. 1-2, Kluwer Academic Publishers.

JAJI, Tsitsi Ella. (2014). Africa in Stereo: Modernism, Music, and Pan-African Solidarity. Oxford: Oxford University Press.

KIRKLEY, Christopher. (2015). Music from Cellphones - West Africa. In: MAIGRET, Nicolas; ROSZKOWSKA, Maria. The Pirate Book. Ljubljana: Aksioma - Institute for Contemporary Art.

KRAEMER, Kenneth L.; DEDRICK, Jason; SHARMA, Prakul. (2009). One Laptop Per Child: Vision vs. Reality. Communications of the ACM, v. 52, n. 6. 
KRZYWDZINSKI, Martin; GERBER, Christine; EVERS, Maren. (2018). The Social Consequences of the Digital Revolution. Le grandi questioni sociali del nostro tempo: a partire da Luciano Gallino. Società e trasformazioni sociali, 6, Veneza.

LARKIN, Brian. (2005). Nigerian Video: the Infrastructure of Piracy. Politique africaine, 4, n. 100, Editions Karthala.

LOVELUCK, Benjamin. (2018). Redes, Liberdades e Controle: uma genealogia política da internet: Petrópolis: Vozes.

MBEMBE, Achille. (2002). The Power of the Archive and its Limits. In: HAMILTON, Carolyn et al. Refiguring the Archive. London: Kluwer Academic Publishers.

MNJAMA, Nathan. (2014). The records management paradigm shift: problems and prospects in East and Southern Africa. In: BWALYA, Kelvin Joseph; MNJAMA, Nathan Mwakoshi; SEBINA, Peter Mazebe II Mothataesi. In: Concepts and Advances in Information Knowledge Management: Studies from Developing and Emerging Economies. Amsterdam: Chandos Publishing.

MOLINARI, Aleph. (2019). Bridging the Digital Divide (Vídeo). San Miguel de Allende: TEDx Talk, 2011. 10min. Disponível em: encurtador.com.br/fqLPZ. Acesso em: 22 jul.

MOROZOV, Evgeny. (2018). Big Tech: a ascensão dos dados e a morte da política. São Paulo: Ubu Editora.

NANNYONGA-TAMUSUZA, Sylvia; WEINTRAUB, Andrew N. (2012). The Audible Future: Reimagining the Role of Sound Archives and Sound Repatriation in Uganda. Ethnomusicology, v. 56, n. 2.

NOBLE, Safiya Umoja. (2018). Algorithms of Oppression. How Search Engines Reinforce Racism. New York: New York University Press.

SARKAR, Avijit; PICK, James B. (2015). The Global Digital Divides: Explaining Change. New York: Springer.

SCHMIDT, Eric James. (2018). Rhythms of Value: Tuareg Music and Capitalist Reckonings in Niger. Dissertation for the degree Doctor of Philosophyin Ethnomusicology. Los Angeles: University of California.

SCHWARTZ, Joan M.; COOK, Terry. (2002). Records, and Power: The Making of Modern Memory. Archival Science, v.2, n. 1-2, Kluwer Academic Publishers.

SPYER, Juliano. (2017). Social Media in Emergent Brazil: How the Internet Affects Social Change. London: UCL Press.

SRINUAN, Chalita; BOHLIN, Erik. (2011). Understanding the digital divide: a literature survey and ways forward. 22nd European Regional Conference of the International Telecommunications Society (ITS2011), Budapest.

SUMPTER, David. (2019). Dominados pelos números: do Facebook e Google às fake news, os algoritmos que controlam nossas vidas. Rio de Janeiro: Bertrand Brasil.

THRAM, Diane. (2012). Performing the archive: The ILAM For Future Generations exhibit, Music Heritage Project SA and Red Location Music History Project. In: 
MONTANO, Ed; NARDI, Carlo (Eds.). Situating popular musics: IASPM 16th International Conference Proceedings. Granhamstwon: IASPM.

TSOU, Judy; VALLIER, John. (2016). Ether Today, Gone Tomorrow: 21st Century Sound Recording. Notes, v. 72, n. 3, mar.

VAIDHYANATHAN, Siva. (2011). A googlelização de tudo: (e por que devemos nos preocupar): a ameaça do controle total da informação por meio da maior e mais bemsucedida empresa do mundo virtual. São Paulo: Cultrix.

WITT, Stephen. (2015). Como a música ficou grátis: o fim de uma indústria, a virada do século e o paciente zero da pirataria. Rio de Janeiro: Intrínseca.

YA'U, Yunusa Zakari. (2004). The new imperialism \& Africa in the global electronic village. Review of African Political Economy, Vol.31, 99.

ZUBOFF, Shoshana. (2018). Big Other: capitalismo de vigilância e perspectivas para uma civilização de informação. In: BRUNO, Fernanda et al (org.). Tecnopolíticas da vigilância: perspectivas da margem. São Paulo: Boitempo.

ZUBOFF, Shoshana. (2019). The age of surveillance capitalism: the fight for a human future at the new frontier of power. New York: PublicAffairs.

\section{sobre o autor}

\section{Renato de Lyra Lemos}

Doutorando do Programa de Pós-Graduação em Antropologia da Universidade Federal de Pernambuco (PPGA-UFPE). Pesquisador do Laboratório de Estudos Avançados de Cultura Contemporânea (LEC-UFPE), do Observatório de Museus e Patrimônios Culturais (OBSERVAMUS), do Instituto de Estudos da África (IEAfUFPE) e do Museu Afro-Digital da Memória Africana e AfroBrasileira (UFBA). 